\title{
A bibliometric analysis of exertional heat stroke research in Web of Science
}

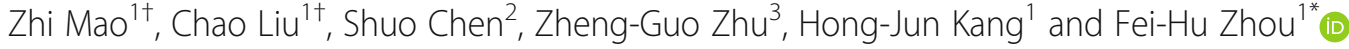

\begin{abstract}
Background: Exertional heat stroke is a fatal condition and remains a health problem. This paper evaluates the publication trend regarding exertional heat stroke research between 1996 and 2015 using a bibliometric method.

Method: Articles regarding exertional heat stroke research published between 1996 and December 2015 were searched for in the SCI-EXPANDED database of Web of Science. The search results were analyzed with regard to publication year; publication quantity regarding countries/regions, and authors; citation frequency; and journal distribution. CiteSpace (v3.6) was used for a document co-citation visualization analysis.

Results: In total, 289 publications on heat stroke were located. After selection, 209 original articles conducted across 28 countries/regions and published in 83 journals were included in the analysis. The USA, Isreal, and France were the most common locations for exertional heat stroke studies. The CiteSpace visualization cluster analysis showed that exertional heat stroke-related mortality and protective measures were constant concerns of research.
\end{abstract}

Conclusions: Research related to exertional heat stroke has been continuous concerned. USA is still the leading country in this field.

Keywords: Heat stroke, Bibliometric analysis

\section{Background}

Heat stroke is a severe and fatal condition clinically characterized by a severe rise in core body temperature (often $>40{ }^{\circ} \mathrm{C}$ ), with concomitant central nervous system dysfunctions such as delirium, convulsions, epilepsy, and coma [1]. Heat stroke is primarily classified into classic heat stroke and exertional heat stroke. The latter is particularly encountered during modern warfare and military training. Over the past few decades, the incidence of exertional heat stroke has significantly increased. According to data from the US Centers for Disease Control and Prevention, 7,000 cases of heat stroke death occurred in the US between 1979 and 1997 [2]. Along with the change in global climate, the progress of urbanization, and the extension of life expectancy, exertional heat stroke is expected to remain a health problem that cannot be ignored [3]. The most common

* Correspondence: feihuzhou301@126.com

${ }^{\dagger}$ Equal contributors

${ }^{1}$ Department of Critical Care Medicine, Chinese PLA General Hospital, Beijing

100853, China

Full list of author information is available at the end of the article treatment for exertional heat stroke is rapid cooling to promptly lower body temperature to normal. This strategy can reduce the risk of organ damage [4]. Despite effective cooling, numerous patients suffer from multiple organ failure, disability, and even death following active cooling treatment. Several studies related to exertional heat stroke have been published over the last few decades [1-3]. However, many problems remain to be addressed regarding the pathogenesis, prevention, and treatment of exertional heat stroke [3]. Bibliometric analysis is a wildly used method to evaluate the publication trend on a special topic [5].

Although many papers investigated exertional heat stroke, reports are still currently lacking regarding the trend of exertional heat stroke publications. We aimed to employ a bibliometric method to analyze the trend of exertional heat stroke publication in the latest twenty years.

\section{Methods}

This trend analysis was performed using the Web of Science database with regard to publication quantity, 
country/region, institution, author, journal, and so on. The co-citation patterns were visualized to provide evidence for relevant clinics and research.

\section{Data source and retrieval}

The SCI-EXPANDED database of Web of Science was searched, and the last search occurred on June 14, 2016. The search terms "heat stroke" or "heatstroke" and "exertional" were used to create the following search queries: (topic $=$ "heat stroke") OR (topic = heatstroke) ) AND "exertional". The time span was set to between 1996 and 2015. The publication type was not limited, and "article" was selected for an in-depth analysis.

\section{Statistical analyses}

Histcite 12.03.07 (Thomson Reuters) was used for the descriptive analysis. A bibliometric method was used to quantitatively describe the published articles regarding year of publication; publication quantity, including country/ region, institution, and author; citation frequency; and journal distribution. A citation map was generated. The co-citation visualization analysis was performed using CiteSpace 3.6.

\section{Results}

\section{Selection of articles}

Using the search queries, 289 publications were searched, including 209 original articles, 37 reviews, 11 editorials, 10 meeting abstracts, 10 letters, 8 proceedings papers, 4 corrections. Based on the selection criteria, 80 nonoriginal articles were excluded, and 209 original articles related to exertional heat stroke were included in the analysis.

\section{Distribution of articles by publication years}

The quantity of published articles on exertional heat stroke showed an overall trend by year, which rose from 12 in 1996 to 31 in 2015 (Table 1).

\section{Distribution of articles by countries and regions}

The 209 articles originated from 28 countries and regions. The USA, Isreal, France, Mainland China and Taiwan, and UK were the most common locations for publishing articles on exertional heat stroke (Table 2). USA is the leading country during the twenty years in publishing articles on exertional heat stroke.

\section{Distribution of articles by authors}

The 209 articles were written by 803 authors in total. The top 10 authors publishing articles on exertional heat stroke primarily came from the US and Israel (Table 3). Casa DJ from the University Connecticut of USA published the most articles (20 records) and accounted for $9.6 \%$ of all published articles. Casa DJ published the first
Table 1 Number and citation frequency of published articles on extertional heat stroke between 1996 and 2016

\begin{tabular}{|c|c|c|c|}
\hline Publication year & Articles & Citation frequency & $\begin{array}{l}\text { Average citation } \\
\text { frequency }\end{array}$ \\
\hline 1996 & 12 & 485 & 40.4 \\
\hline 1997 & 4 & 38 & 9.5 \\
\hline 1998 & 6 & 105 & 17.5 \\
\hline 1999 & 3 & 135 & 45.0 \\
\hline 2000 & 1 & 24 & 24.0 \\
\hline 2001 & 6 & 82 & 13.7 \\
\hline 2002 & 6 & 93 & 15.5 \\
\hline 2003 & 10 & 98 & 9.8 \\
\hline 2004 & 11 & 318 & 28.9 \\
\hline 2005 & 7 & 213 & 30.4 \\
\hline 2006 & 12 & 244 & 20.3 \\
\hline 2007 & 12 & 250 & 20.8 \\
\hline 2008 & 7 & 117 & 16.7 \\
\hline 2009 & 10 & 192 & 19.2 \\
\hline 2010 & 11 & 151 & 13.7 \\
\hline 2011 & 16 & 120 & 7.5 \\
\hline 2012 & 9 & 111 & 12.3 \\
\hline 2013 & 12 & 61 & 5.1 \\
\hline 2014 & 23 & 43 & 1.9 \\
\hline 2015 & 31 & 43 & 1.4 \\
\hline Total & 209 & 2923 & 14.0 \\
\hline
\end{tabular}

article on exertional heat stroke in 2005 [6]; the most recent research on exertional heat stroke was published in 2015 [7].

\section{Distribution of articles by journals}

The 209 articles were published across 105 journals. The top 10 journals published 83 articles on heat stroke and accounted for $32.9 \%$ of all articles included in this study (Table 4). The JOURNAL OF ATHLETIC TRAINING published the most articles (16). Ellis A published the most frequently cited article in Gut in 1996 which was referenced 102 times [8].

\section{Citation map}

One of the core documents cited was published by Epstein Y in 1999, titled "Exertional heat stroke: a case series" [9]. Another core document cited was published by Smith JE in 2005, titled "Cooling methods used in the treatment of exertional heat illness" [10] (Fig. 1).

\section{Analysis of time-frequency of key words}

The time frequency of the keywords was obtained via a co-citation analysis using CiteSpace (Fig. 2). The core 
Table 2 An analysis of the number and citation frequency of published articles with regard to major countries/regions

\begin{tabular}{|c|c|c|c|c|c|c|c|c|c|c|c|c|c|c|c|c|c|c|c|c|c|c|c|}
\hline \multirow[t]{2}{*}{ Rank } & \multirow[t]{2}{*}{ Country/region } & \multirow{2}{*}{$\begin{array}{l}\text { Total } \\
\text { records }\end{array}$} & \multicolumn{20}{|c|}{ Publication year } & \multirow{2}{*}{$\begin{array}{l}\text { Total } \\
\text { citation }\end{array}$} \\
\hline & & & 1996 & 1997 & 1998 & 1999 & 2000 & 2001 & 2002 & 2003 & 2004 & 2005 & 2006 & 2007 & 2008 & 2009 & 2010 & 2011 & 2012 & 2013 & 2014 & 2015 & \\
\hline 1 & USA & 105 & 8 & 0 & 3 & 0 & 1 & 3 & 4 & 4 & 3 & 3 & 7 & 6 & 2 & 4 & 7 & 10 & 3 & 5 & 10 & 22 & 1725 \\
\hline 2 & Israel & 19 & 0 & 0 & 0 & 1 & 0 & 0 & 1 & 2 & 6 & 0 & 2 & 0 & 0 & 0 & 0 & 4 & 1 & 1 & 1 & 0 & 266 \\
\hline 3 & France & 14 & 1 & 1 & 0 & 1 & 0 & 1 & 0 & 0 & 0 & 1 & 1 & 0 & 1 & 1 & 2 & 0 & 0 & 0 & 2 & 2 & 177 \\
\hline 4 & Mainland China & 13 & 0 & 0 & 0 & 0 & 0 & 0 & 0 & 0 & 0 & 0 & 0 & 1 & 0 & 0 & 0 & 2 & 1 & 1 & 4 & 4 & 37 \\
\hline 5 & UK & 12 & 1 & 0 & 0 & 0 & 0 & 0 & 0 & 0 & 0 & 1 & 0 & 2 & 1 & 0 & 0 & 0 & 1 & 2 & 0 & 4 & 283 \\
\hline 6 & Taiwan & 11 & 1 & 2 & 0 & 0 & 0 & 0 & 0 & 1 & 2 & 0 & 0 & 0 & 0 & 0 & 2 & 1 & 1 & 0 & 1 & 0 & 109 \\
\hline
\end{tabular}


Table 3 Ten authors who published at least 10 articles on exertional heat stroke from 1996 to 2016

\begin{tabular}{llllcll}
\hline Rank & Author & Records & Citations & Average citation & Country/region & Institution \\
\hline 1 & Casa DJ & 20 & 302 & 15.1 & USA & University Connecticut \\
2 & Armstrong LE & 12 & 325 & 27.1 & USA & University Connecticut \\
3 & Epstein Y & 9 & 253 & 28.1 & Israel & Tel Aviv University \\
4 & Moran DS & 9 & 203 & 22.6 & Israel & Tel Aviv University \\
5 & Roberts WO & 8 & 241 & 30.1 & USA & University of Minnesota \\
6 & Wenger CB & 8 & 255 & 31.9 & USA & US Army Research Institute of Environmental Medicine \\
7 & Heled Y & 7 & 131 & 18.7 & Israel & Heller Institute of Medical Research \\
8 & Maresh CM & 7 & 193 & 27.6 & USA & University Connecticut \\
9 & Gardner JW & 6 & 191 & 31.8 & USA & Uniformed Services University of the Health Sciences \\
10 & McDermott BP & 6 & 114 & 19.0 & USA & University of Tennessee \\
\hline
\end{tabular}

documents co-cited were subject to a cluster analysis (Table 5). Fifteen categories were generated in the cluster analysis, with the following nine major categories: "fulminant hepatic failure", "contribution", "near-fatal exertional heat stroke", "plasma beta-endorphin concentration", "marine corp", "suspected heat illness", "distance", "air force", and "energy metabolism" et al. In this figure, the timeline of clusters labeled using keywords is shown horizontally. The earliest concern was "marine corp".

\section{Discussion}

According to classical bibliometric theory, increases or decreases in the number of scientific research publications indicate the speed of scientific/technological development. The present study shows that the number of published research articles on exertional heat stroke between 1996 and 2015. These publications indicate several findings. First, heat stroke research has been of continuous concern. Second, environmental heat damage, sports heat damage, and military action training heat damage remain problems that cannot be ignored. Finally, many problems have yet to be solved regarding the diagnosis, treatment, and prognosis of heat stroke.

With regard to distribution by country/region, US and Israel are the two leading countries. Mainland China published the most articles on heat stroke ranking No.4. Previous bibliometric studies in other fields have also found a sharp increase in the number of research articles from Mainland China, exceeding Hong Kong and Taiwan [11-13] and ranking second only to the US [14]. The continuous research progress in the number of published articles on exertional heat stroke demonstrates the overall improvements in critical care medicine, sports medicine, and military medicine in the output country.

With respect to journal distribution, the top 10 journals publishing articles on exertional heat stroke were all specialist publications, and none were comprehensive. On one hand, this evidence indicates that exertional heat stroke research is relatively esoteric. Most of these top

Table 4 Top ten $\mathrm{SCl}$ journals for heat stroke publications

\begin{tabular}{|c|c|c|c|c|}
\hline Journals & Records & Categories & Quartile & F2014 \\
\hline Journal of athletic training & 16 & Sport sciences & Q2 & 2.017 \\
\hline Medicine and science in sports and exercise & 16 & Sport sciences & Q2 & 3.983 \\
\hline Military medicine & 12 & Medicine, general \& internal & Q3 & 0.911 \\
\hline Aviation space and environmental medicine & 8 & $\begin{array}{l}\text { Medicine, general \& internal/public, environmental \& } \\
\text { occupational health/sport sciences }\end{array}$ & Q3/Q4/Q5 & 0.875 \\
\hline Journal of applied physiology & 7 & Physiology/sport sciences & Q2/Q1 & 3.056 \\
\hline Wilderness \& environmental medicine & 6 & Public, environmental \& occupational health/sport sciences & Q3/Q3 & 1.196 \\
\hline European journal of applied physiology & 5 & Physiology/sport sciences & Q3/Q2 & 2.187 \\
\hline Journal of thermal biology & 5 & Biology/zoology & Q2/Q2 & 1.505 \\
\hline American family physician & 4 & Primary health care/medicine, general \& internal & Q1/Q2 & 2.175 \\
\hline Journal of strength and conditioning research & 4 & Public, environmental \& occupational health/sport sciences & Q3/Q3 & 1.196 \\
\hline
\end{tabular}




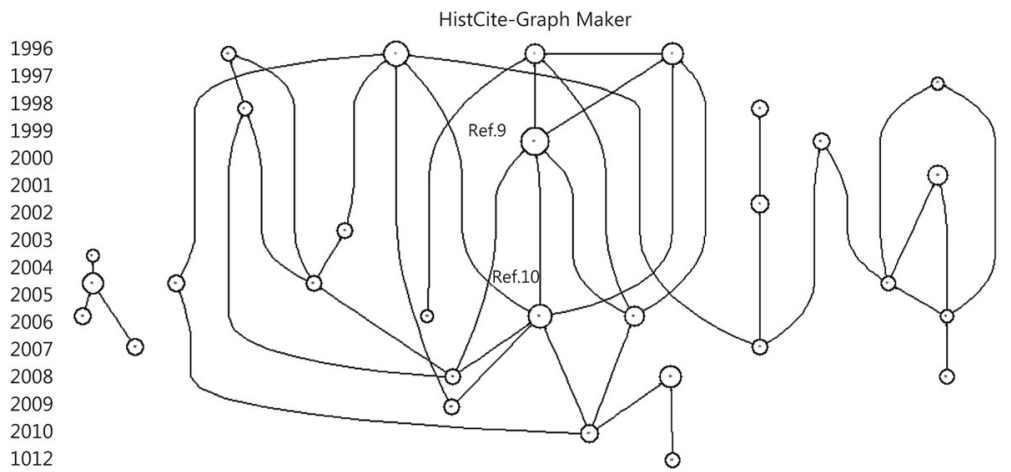

Fig. 1 A citation map, with Ref 9 and Ref 10 as core documents

10 journals were classified as quartile 2 or 3 SCI publications. These journals mainly focus on Sport Science or Military Medicine. Although impact factor has been extensively used to evaluate the quality of research published [15], its value has always been questioned. Professor Alberts, the editor-in-chief of Science, the top journal in the sciences, recently published an editorial stating that impact factor has led to abnormalities in the research evaluation system [16]. Moreover, high impact factor journals occasionally publish low-quality research. Therefore, we did not analyze or discuss impact factor in the present study.

Recently, an increasing number of bibliometric analyses have emerged in medicine [11-13, 17-20] and have demonstrated significant value [21]. Previous analyses have shown that the number of published articles grew rapidly in certain countries that are emerging in scientific research, which reduced the share of articles from traditional research powers in Europe and the US [22]. A 2010 study showed that 100 classic publications in Bone Science were primarily from the UK and the US [23]. The authors of that study predicted that China would reverse this situation and establish a new balance in the near future [21]. As the present study revealed, this trend has begun to show in heat stroke research. Furthermore, we performed a visualization cluster analysis of co-cited documents on heat stroke and listed core documents in these clusters.

The present study has a few limitations. For example, to perform the citation analysis, we only searched the SCI database and not the Medline or Embase databases. However, we are certain that the SCI database generally includes all mainstream documents in the natural sciences.



Fig. 2 Timeline for the keyword analysis of the document co-citation clustering 
Table 5 Documents at the nodes of the co-citation clusters

\begin{tabular}{lccl}
\hline $\begin{array}{l}\text { Frequency } \\
\text { (cited times) }\end{array}$ & $\begin{array}{l}\text { Centrality (article's degree } \\
\text { of centralized in the cluster) }\end{array}$ & Year & Co-cited articles \\
\hline 84 & 0.30 & 2002 & Bouchama A, 2002, New Engl J Med, V346, P1978, DOI 10.1056/NEJMRA011089 \\
51 & 0.06 & 2007 & Armstrong LE, 2007, Med Sci Sport Exer, V39, P556, DOI 10.1249/MSS.0B013E31802FA199 \\
35 & 0.31 & 1990 & Costrini A, 1990, Med Sci Sport Exer, V22, P15 \\
30 & 0.06 & 1990 & Shapiro Y, 1990, Med Sci Sport Exer, V22, P6 \\
29 & 0.17 & 1999 & Epstein Y, 1999, Med Sci Sport Exer, V31, P224, DOI 10.1097/00005768-199902000-00004 \\
28 & 0.09 & 2007 & Casa DJ, 2007, Exerc Sport Sci Rev, V35, P141 \\
27 & 0.10 & 2005 & Casa DJ, 2005, Curr Sport Med Rep, V4, P309 \\
24 & 0.07 & 1996 & Armstrong LE, 1996, Am J Emerg Med, V14, P355, DOI 10.1016/S0735-6757(96)90048-0 \\
23 & 0.04 & 1967 & Shibolet S, 1967, Q J Med, V36, P525 \\
22 & 0.28 & 2003 & Proulx Cl, 2003, J Appl Physiol, V94, P1317, DOI 10.1152/JAPPLPHYSIOL.00541.2002 \\
22 & 0.17 & 1998 & Dematte JE, 1998, Ann Intern Med, V129, P173 \\
22 & 0.11 & 2005 & Smith JE, 2005, Brit J Sport Med, V39, P503, DOI 10.1136/BJSM.2004.013466 \\
22 & 0.09 & 2002 & Bouchama A, 2002, New Engl J Med, V346, P1978, DOI 10.1056/NEJMRA011089 \\
21 & 0.13 & & \\
84 & 0.30 & &
\end{tabular}

\section{Conclusions}

In summary, the research evidence gained continous attention in exertional heat stroke-related fields. USA is the dominated country in this field.

\section{Abbreviation}

SCl: Science Citation Index

\section{Funding}

None.

\section{Availability of data and materials}

All data generated or analyzed during this study are included in this published article [and its supplementary information files].

\section{Authors' contributions}

$\mathrm{ZM}$ and $\mathrm{CL}$ contributed equally to this work. $\mathrm{ZM}$ and $\mathrm{CL}$ conceived the study, participated in the design, collected the data, performed statistical analyses, and drafted the manuscript. SC performed statistical analyses, and helped to draft the manuscript. ZGZ and HJK revised the manuscript critically for important intellectual content. FHZ performed statistical analyses, helped to revise the manuscript critically for important intellectual content. All authors read and approved the final manuscript.

\section{Competing interests}

The authors declare that they have no competing interests.

\section{Consent for publication}

Not applicable.

\section{Ethics approval and consent to participate}

Not applicable.

\section{Author details}

'Department of Critical Care Medicine, Chinese PLA General Hospital, Beijing 100853, China. ${ }^{2}$ Department of Medical Information, Chinese PLA General Hospital, Beijing 100853, China. ${ }^{3}$ Department of Orthopedics, Chinese PLA General Hospital, Beijing 100853, China.
Received: 24 March 2016 Accepted: 10 October 2016

Published online: 20 October 2016

\section{References}

1. Bouchama A, Knochel JP. Heat stroke. N Engl J Med. 2002;346(25):1978-88.

2. Centers for Disease Control and Prevention (CDC). Heat-related illnesses, deaths, and risk factors-Cincinnati and Dayton, Ohio, 1999, and United States, 1979-1997. MMWR Morb Mortal Wkly Rep. 2000;49(21):470-3.

3. Leon LR, Bouchama A. Heat stroke. Compr Physiol. 2015;5(2):611-47.

4. Szold O, Reider II G, Ben Abraham R, Aviram G, Segev Y, Biderman P, et al. Gray-white matter discrimination-a possible marker for brain damage in heat stroke? Eur J Radiol. 2002;43(1):1-5

5. Guler AT, Waaijer CJ, Palmblad M. Scientific workflows for bibliometrics. Scientometrics. 2016:107:385-98.

6. Yeargin SW, Casa DJ, McClung JM, Knight JC, Healey JC, Goss PJ. Body cooling between two bouts of exercise in the heat enhances subsequent performance. J Strength Cond Res. 1995;37(6):595-8.

7. Chao CM, Cheng BC, Chen CY, Lin MT, Chang CP, Yang ST. Proteomic analysis of hypothalamic injury in heatstroke rats. Proteomics. 2015;15(11):1921-34.

8. Ellis AJ, Wendon JA, Portmann B, Williams R. Acute liver damage and ecstasy ingestion. Gut. 1996;38(3):454-8.

9. Epstein Y, Moran DS, Shapiro Y, Sohar E, Shemer J. Exertional heat stroke: a case series. Med Sci Sports Exerc. 1999;31(2):224-8.

10. Simith JE. Cooling methods used in the treatment of exertional heat illness. Br J Sports Med. 2005;39(8):503-7.

11. Li Z, Liao Z, Wu FX, Yang LQ, Sun YM, Yu WF. Scientific publications in critical care medicine journals from Chinese authors: a 10-year survey of the literature. J Trauma. 2010:69(4):E20-3.

12. Cheng $T$. Research in orthopaedics from China has thrived over the last decade: a bibliometric analysis of publication activity. Orthop Traumatol Surg Res. 2012;98(3):253-8.

13. Cheng T, Zhang X. Growing trend of China's contribution to the field of rheumatology 2000-2009: a survey of Chinese rheumatology research. J Rheumatol. 2010;37(11):2390-4.

14. Mao Z, Wang G, Mei X, Chen S, Liu X, Zeng X, et al. Systematic reviews on reports of hip fractures in Web of Science: a bibliometric analysis of publication activity. Chin Med J (Engl). 2014;127(13):2518-22.

15. Smith R. Beware the tyranny of impact factors. J Bone Joint Surg (Br). 2008:90(2):125-6.

16. Alberts B. Impact factor distortions. Science. 2013;340(6134):787. 
17. Michalopoulos A, Falagas ME. A bibliometric analysis of global research production in respiratory medicine. Chest. 2005;128(6):3993-8.

18. Zhang XY, Xie K, Yang XR, Li FW, Yin L, Cheng J. Analysis of status of citation of articles published in the Medical Journal of Chinese PLA from 2000 to 2009. Med J Chin PLA. 2012;37(12):1165-7.

19. Gao XY, Ma L, Cui ZS, Li CJ, Li SM. International research focuses of risk management of medical devices: A bibliometric analysis. Chin J Evid-based Med. 2014;6:691-7.

20. Jiang LH, Shen JT, Li YP, Deng SL, Wu TX, Chen BQ, et al. Medical ethics: subject, function, and trends: A comparative study of medical ethics in Chinese and English bibliometric. Chin J Evid-based Med. 2012:5:542-9.

21. Migaud $\mathrm{H}$. Why publish a survey of orthopaedic scientific production from China? Orthop Traumatol Surg Res. 2012;98(3):251-2.

22. Franzoni C, Scellato G, Stephan P. Science policy. Changing incentives to publish. Science. 2011;333(6043):702-3.

23. Kelly JC, Glynn RW, O'Briain DE, Felle P, McCabe JP. The 100 classic papers of orthopaedic surgery: A bibliometric analysis. J Bone Joint Surg (Br). 2010;92B(10):1338-43.

Submit your next manuscript to BioMed Central and we will help you at every step:

- We accept pre-submission inquiries

- Our selector tool helps you to find the most relevant journal

- We provide round the clock customer support

- Convenient online submission

- Thorough peer review

- Inclusion in PubMed and all major indexing services

- Maximum visibility for your research

Submit your manuscript at www.biomedcentral.com/submit 